\title{
Anticoccidial Efficacy of Medium-Chain Triglycerides (MCT) in Calves
}

\author{
Hiroshi SATO $^{1)}$, Atushi NITANAI ${ }^{1)}$, Takashi KUROSAWA ${ }^{1)}$ and Shin OIKAWA ${ }^{1)}$ \\ ${ }^{1)}$ Department of Large Animal Clinical Science, School of Veterinary Medicine, Rakuno Gakuen University, Ebetsu, Hokkaido 069-8501, \\ Japan
}

(Received 26 March 2004/Accepted 21 July 2004)

ABSTRACT. Anticoccidial efficacy of dietary fat was evaluated in calves with coccidial infection (Eimeria spp., including E. bovis and E. zuernii). Medium-chain triglycerides (MCT) - natural edible fats composed of caprylic $\left(\mathrm{C}_{8}\right)$, capric $\left(\mathrm{C}_{10}\right)$, and lauric $\left(\mathrm{C}_{12}\right)$ acids - were given orally with milk to 5 calves and with $10 \%$ glucose solution to 3 older, weaned calves by using the reticular groove reflex. After 3 to 11 days of MCT feeding, all Eimeria spp. oocysts had disappeared from the feces of all calves. MCT had no adverse effects on appetite or on fecal $\mathrm{pH}$, ammonia, lactic acid, or volatile fatty acid levels. MCT feeding for coccidial control in calves has minimal sideeffects and has benefits in terms of residue-free food production.

KEY WORDS: calf coccidia, coccidiostats, medium-chain triglyceride.

J. Vet. Med. Sci. 66(12): 1583-1585, 2004

Coccidial infection causes occasionally severe diarrhea in young farm animals, including calves. To eliminate coccidia, veterinarians and farm managers use several drugs, including ionophore antibiotics, sulfonamides, and the thiamine analog amprolium, despite their side effects in the host animals. It is well known that some fatty acids and their derivatives have toxic effects on rumen protozoa in cattle [10] and small ruminants [7]. The defaunative [7] and antibacterial [2] effects of capric acid $\left(\mathrm{C}_{10}\right)$ and its derivatives are stronger than those of fatty acids with shorter or longer carbon chains. The fatty acids with chain lengths of $8\left(\mathrm{C}_{8}\right.$; caprylic acid) to $12\left(\mathrm{C}_{12}\right.$; lauric acid $)$ are collectively called medium-chain fatty acids (MCFA), and their derivative triglycerides are known as medium-chain triglycerides (MCT). From the toxic action of MCFA on rumen protozoa [7, 10], we hypothesized that MCFA or MCT might also be toxic to parasitic coccidia in the gut. In this note, young calves were treated with MCT composed mainly of $\mathrm{C}_{8}$ to $\mathrm{C}_{12}$ to elucidate the anticoccidial efficacy of these fatty acids.

Eight Holstein calves ( 1 to 6 months; one had been crossbred with a Japanese Black) were used in a barn. Five (48 to $78 \mathrm{~kg}$ ) were being fed milk with solid diets, and the other weaned three ( 85 to $140 \mathrm{~kg}$ ) were no longer receiving milk. All 8 calves had become infected spontaneously with coccidia (Eimeria spp., including E. bovis and E. zuernii, as determined by microscopic examination of feces), but only two (both milk-fed calves) showed diarrhea. Coccidial infection of the calves was sporadic, and MCT was given sporadically after confirmation of oocyst in the feces. There was a wide variation in the fecal excretion of oocysts among the 8 calves: the coccidial oocyst counts per gram of feces (OPG) ranged from 96 to 21700 . Control calves with coccidial infection were not included because this small herd had insufficient numbers of calves with sporadic infection. The efficiency of coccidial elimination was evaluated by fecal output of oocysts. The animals were cared for and handled in accordance with the Laboratory Animal Control Guidelines of Rakuno Gakuen University, which conform to the USA National Institutes of Health Guidelines for the Care and Use of Laboratory Animals.

The MCT (Kao, Tokyo) was liquid at room temperature, and its specific gravity was 0.95 . It was also safe for human consumption. The component fatty acids were $55 \% \mathrm{C}_{8}$, $30 \% \mathrm{C}_{10}, 11 \% \mathrm{C}_{12}$, and $4 \%$ other (Fig. 1) according to our laboratory analysis. The five milk-fed calves received 40 to $100 \mathrm{ml}$ of MCT with either the morning or evening feeding of milk. Beforehand the MCT feeding in three weaned calves, reticular groove reflex was re-acquired by teat-feeding of a $10 \%$ glucose solution. For direct administration into the abomasum, not into the rumen, the weaned calves received 50 to $300 \mathrm{~m} l$ of MCT with $1 l$ of $10 \%$ glucose solution by teat feeding.

Details of daily dosages, duration (days) of MCT treatment, and OPG values are given in Table 1. Fecal samples were taken directly from the rectum daily, and coccidial oocyst output was evaluated by means of the sucrose flotation method. MCT treatment was stopped after 2 consecutive days of negative oocyst output in the feces. Fecal samples of 4 calves (two each milk-fed and weaned) were submitted for examination of $\mathrm{pH}$ and fermentative properties. Each 5-g sample of fresh feces was mixed well with 20 $\mathrm{m} l$ of water and the $\mathrm{pH}$ was recorded. The mixture was centrifuged at about $2000 \times \mathrm{g}$, and the supernatant was frozen at $-30^{\circ} \mathrm{C}$ until analysis. Fecal ammonia and lactic acid were analyzed colorimetrically by means of a previously described method [11]. Fecal volatile fatty acids (VFA) were analyzed by gas chromatography equipped with FALM (Shimadzu, Kyoto, Japan) filling column and flame ionization detector, using diethylacetic acid as an internal standard. We also used gas chromatography with a Shinchrome E71 (Shimadzu, Kyoto, Japan) column to evaluate the fatty acid profile of the MCT used.

In 4 calves, we used analyses of variance to compare the above fecal properties before MCT treatment, during MCT feeding, and after coccidial elimination. The size of the samples taken during MCT treatment differed among the 4 


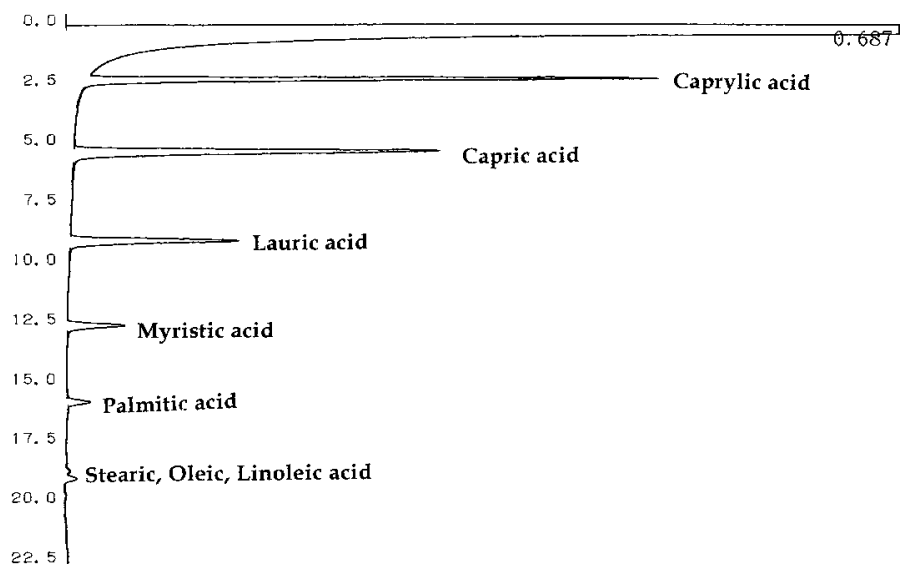

Fig. 1 Fatty acid composition of MCT (Gas chromatogram)

Table 1. Disappearance of fecal coccidial oocyst in calves after MCT feeding

\begin{tabular}{cccccccc}
\hline & Meal & Age & Live wt. & MCT fed. & \multicolumn{2}{c}{ OPG* } & Days until \\
Calf & & $(\mathrm{m})$ & $(\mathrm{kg})$ & $(\mathrm{m} / /$ day $)$ & Before & After & disappearance \\
\hline 1 & Milk & 1 & 48 & $50 \rightarrow 60^{* *}$ & 900 & 0 & 4 \\
2 & Milk & 2 & 72 & 40 & 96 & 0 & 3 \\
3 & Milk & 2 & 56 & 50 & 790 & 0 & 5 \\
4 & Milk & 2 & 78 & 50 & $>400$ & 0 & 3 \\
5 & Milk & 3 & 58 & 100 & 21700 & 0 & 10 \\
6 & Weaning & 3 & 85 & $50 \rightarrow 100^{* * *}$ & 11850 & 0 & 11 \\
7 & Weaning & 5 & 140 & $100 \rightarrow 300^{* * *}$ & 273 & 0 & 9 \\
8 & Weaning & 6 & 140 & 100 & 158 & 0 & 4 \\
\hline
\end{tabular}

* Oocyst per one gram of feces.

$* *$ Starting dose $\rightarrow$ Last dose.

Table 2. Fecal properties during MCT feeding for coccidial elimination in calves

\begin{tabular}{|c|c|c|c|c|c|c|c|c|}
\hline $\begin{array}{l}\text { Calf } \\
\text { Meal }\end{array}$ & Stage* & $\mathrm{pH}$ & $\begin{array}{c}\text { Ammonia } \\
\mathrm{mM}\end{array}$ & $\begin{array}{c}\text { Lactic acid } \\
\text { mM }\end{array}$ & $\begin{array}{l}\text { VFA } \\
\mathrm{mM}\end{array}$ & $\begin{array}{c}\text { Acetic } \\
\%\end{array}$ & $\begin{array}{c}\text { Propionic } \\
\%\end{array}$ & $\begin{array}{c}\text { Butyric } \\
\%\end{array}$ \\
\hline 3 & Before $(2)^{* *}$ & 6.99 & 18.6 & 0.48 & 178.8 & 52.9 & 24.0 & 15.1 \\
\hline \multirow[t]{2}{*}{ On milk } & Middle (1) & 7.17 & 8.8 & 0.84 & 125.3 & 56.7 & 19.1 & 15.9 \\
\hline & After (3) & 6.35 & 16.9 & 0.41 & 114.7 & 58.9 & 19.9 & 14.3 \\
\hline 5 & Before (2) & 6.63 & 12.7 & 0.22 & 62.7 & 55.7 & 24.7 & 13.5 \\
\hline \multirow[t]{2}{*}{ On milk } & Middle (7) & 7.08 & 7.8 & 0.17 & 50.9 & 64.2 & 21.3 & 10.4 \\
\hline & After (3) & 7.17 & 16.7 & 0.21 & 59.6 & 56.5 & 22.9 & 13.5 \\
\hline 7 & Before (2) & 6.78 & 5.5 & 0.24 & 36.8 & 67.2 & 18.1 & 11.4 \\
\hline \multirow[t]{2}{*}{ Weaned } & Middle (8) & 6.69 & 4.6 & 0.19 & 36.5 & 66.8 & 17.5 & 12.6 \\
\hline & After (2) & 6.66 & 5.2 & 0.21 & 39.9 & 66.9 & 17.4 & 11.7 \\
\hline 8 & Before (2) & 6.88 & 7.0 & 0.19 & 34.3 & 63.5 & 19.0 & 12.0 \\
\hline \multirow[t]{2}{*}{ Weaned } & Middle (2) & 6.80 & 3.5 & 0.20 & 25.4 & 63.0 & 17.9 & 13.6 \\
\hline & After (3) & 6.85 & 4.7 & 0.21 & 33.0 & 68.9 & 17.6 & 11.1 \\
\hline
\end{tabular}

* Before; Before MCT feeding.

Middle; MCT feeding period with oocyst output.

After; After coccidial elimination.

** Number of samples in parenthesis.

calves: mean fecal values during MCT treatment were derived from 1, 7, 8, and 2 samples, respectively (Table 2).

Table 1 gives data on live weight, changes in coccidial
OPG, quantity of MCT given, and days until coccidial elimination. In milk-fed calves, coccidia were eliminated easily within 3 to 5 days of MCT treatment, except in one calf with 
heavy infection. Prolonged MCT treatment was needed to eliminate coccidia from two calves with heavy (OPG 21700 and 11850) infection and one (calf 7; OPG 273) with mild infection. The diarrhea in the two milk-fed calves (numbers 2 and 5 in Table 1) was cured during MCT feeding. Fecal properties are shown in Table 2. Milk-fed calves showed a tendency toward higher fecal ammonia, lactic acid, and total VFA levels but lower proportions of acetic acid, compared with weaned calves. However, none of these differences was statistically significant.

It is well known that fatty acids or their derivatives inhibit the growth of various bacteria [2]. To avoid potential detrimental effects of fat feeding on rumen bacteria, several delivery methods of fat have been developed during the last two or three decades in dairy industry (e.g., calcium salts of fatty acids, granulated fat or fat derivatives, and modifications of oil seeds) [8]. Unlike bacteria, protozoa are not essential in the rumen [12], and eliminating protozoa (defaunation) has been advantageous in some cases of animal production $[4,12]$. Defaunation has been accomplished experimentally by MCT treatment in goats [7] and calves [10], but little attention had been paid to the anticoccidial effect of MCFA or MCT.

Much of the marketed MCT is manufactured from the seeds of plants such as coconut, other palms, and other tropical plants. Moreover, MCT and MCFA are easily digested and absorbed in the small intestines of mammals, and absorbed MCFA are efficiently metabolized for yielding energy, rather than being deposited in adipose tissue $[1,6$, 9]. From these nutritional standpoints, MCT have been used parenterally $[6,9]$ or as a dietary supplement in human patients with indigestion or malabsorption $[1,3,5]$. From the viewpoint of veterinary and food science, MCT feeding has little side effects in domestic animals and leaves no harmful residues in food products, unlike anticoccidial drugs such as sulfonamides, antibiotics, and amprolium.

Coccidial elimination was confirmed by MCT, although we found a wide variation in the dose and period of MCT feeding needed for successful elimination. This variation might be related to many host factors, including the initial OPG level in each animal. Our results suggest that daily feeding of MCT at $0.05 \%$ to $0.20 \%$ of live weight might be efficient for coccidial removal in young calves, although the dose level may be influenced by many factors, including chain length of MCFA (discussed below).

Which fatty acid is most effective for coccidial elimination is still unclear, because we used MCT mixture composed from 3 fatty acids $\left(\mathrm{C}_{8}, \mathrm{C}_{10}\right.$, and $\left.\mathrm{C}_{12}\right)$. Among the fatty acids, $\mathrm{C}_{10}$ has the strongest antibacterial effect [2]. The fluidity of fats (or triglycerides) at room temperature, which greatly affects the practical ease of their handling and feeding, is influenced by the length of the carbon chain and number of double bonds. Pure MCTs composed of $\mathrm{C}_{10}$ or $\mathrm{C}_{12}$ are solid, but pure MCT composed of $\mathrm{C}_{8}$ is liquid at room temperature. Present crude MCT composed of $\mathrm{C}_{8}, \mathrm{C}_{10}$, and $\mathrm{C}_{12}$ was also liquid at room temperature, and cheaper for using in animal production than pure MCTs composed of a single fatty acid. Our previous studies in beef calves have shown that $\mathrm{C}_{10}$ is more toxic to rumen protozoa than is $\mathrm{C}_{8}$ [10]. Similar results have been obtained in goat rumens using MCFAs, their derivative MCTs, and their calcium salts [7]. The mechanism of the antiprotozoal effects of MCFA or MCT is unclear, but inhibition of cellular uptake of substrates or oxygen has been observed in bacterial experiments [2].

Because of no significant effect of MCT feeding on fecal ammonia, lactic acid, and VFA concentrations, we believe that MCT treatment negligibly affects fermentation functions in the large intestine. Traditional oral feeding of MCT into the rumen, however, has led to several effects on rumen fermentation, including decreased concentrations of ruminal ammonia and VFA, and inactivation of protozoal populations [10]. To be sure of abomasal feeding of MCT in the present experiment, we successfully stimulated the reticular groove reflex by means of teat-feeding of glucose solution. Because the older weaned calves thus drank in the same way as the milk-fed calves, ruminal fermentation was not significantly influenced by the MCT, which flowed straight into the abomasum. For successful use of MCT as a coccidiostat, we need to perform further studies using infected control calves and to determine the optimum chain length and dose level of MCT and the optimum delivery method.

This work was supported by a grant to the High Technology Research Center (Rakuno Gakuen University) from the Ministry of Education, Science, Sports and Culture of Japan.

\section{REFERENCES}

1. Bach, A. C. and Babayan, V. K. 1982. Am. J. Clin. Nutr. 36: 950-962.

2. Freese, E., Sheu, C. W. and Galliers, E. 1973. Nature (Lond.) 241: $321-325$.

3. Hashim, S.A. and Tantibhedyangkul, P. 1987. Lipids 22: 429434.

4. Lapierre, H. and Lobley, G. E. 2001. J. Dairy Sci. 84: E223E236.

5. Leyland, F. C., Fosbrooke, A. S., Lloyd, J. K., Segall, M. M., Tamir, I., Tomkins, R. and Wolff, O. H. 1969. Arch. Dis. Childh. 44: 170-179.

6. Lima, L. A. M. 1989. J. Parent. Ent. Nutr. 13: 312-317.

7. Matsumoto, M., Kobayashi, T., Takenaka, A. and Itabashi, H. 1991. J. Gen. Appl. Microbiol. 37: 439-445.

8. National Research Council, 2001. pp. 28-33. In: Nutrient Requirements of Dairy Cattle. 7th ed., National Academy Press, Washington D.C.

9. Sailer, D. and Müller, M. 1981. J. Parent. Ent. Nutr. 5: 115119.

10. Sato, H., Tsuneishi, E., Hanasaka, S. and Watanabe, A. 1991. Anim. Sci. Tech. 62: 142-147 (in Japanese).

11. Sato, H., Kurosawa, T. and Oikawa, S. 2003. J. Jpn. Vet. Med. Assoc. 56: 517-521 (in Japanese).

12. Veira, D. M. 1986. J. Anim. Sci. 63: 1547-1560. 